\title{
Breeding Peanut for Resistance to Aflatoxin Contamination at ICRISAT
}

\author{
S.N. Nigam ${ }^{1 *}$, F. Waliyar ${ }^{2}$, R. Aruna ${ }^{1}$, S.V. Reddy ${ }^{1}$, P. Lava Kumar ${ }^{3}$, P.Q. Craufurd ${ }^{4}$, A.T. Diallo ${ }^{5}$, B.R. Ntare ${ }^{5}$, and \\ H.D. Upadhyaya ${ }^{1}$
}

\begin{abstract}
Peanut plays an important role in the livelihoods of poor farmers and in the rural economy of many developing countries. Aflatoxin contamination in peanut seeds, caused by Aspergillus flavus, hampers international trade and adversely affects health of consumers of peanut and its products. It can occur in the field when the crop is growing, during harvesting and curing, and in storage and transportation. Aflatoxin research on peanut at ICRISAT focuses on identification and utilization of genetic resistance to preharvest seed infection and aflatoxin production by $A$. flavus and pre and post harvest management practices to minimize contamination. Breeding for aflatoxin resistance has been a contentious issue in peanut for nearly four decades since the first report of host resistance to aflatoxin production by $A$. flavus. Despite global efforts, progress in aflatoxin resistance breeding has been limited due to the low level of resistance to different components of resistance (preharvest seed infection and aflatoxin production, and in vitro seed colonization by $A$. flavus), their variable performance due to high $\mathrm{G} \times \mathrm{E}$ interaction, lack of reliable screening protocols, and limited understanding of genetics of resistance. Efforts to combine the three independently inherited components of resistance did not produce expected results towards improving the host plant resistance to aflatoxin contamination. Although breeding lines have shown better performance for resistance to aflatoxin contamination at ICRISAT, they need wider evaluation under diverse growing conditions. The search for better sources of resistance in the cultivated and wild Arachis germplasm continues, and recent developments in the area of transgenic research through modification of aflatoxin biosynthesis pathway or use of genes with antifungal and anti-aflatoxin properties appear encouraging. Meanwhile, the available improved breeding lines coupled with pre and post harvest aflatoxin management practices can help to significantly
\end{abstract}

\footnotetext{
${ }^{1}$ Principal Scientist, Scientist, Scientific Officer, and Principal Scientist, respectively, ICRISAT, Patancheru 502 324, Andhra Pradesh, India.

${ }^{2}$ Principal Scientist and Director, West and Central Africa, ICRISAT, BP 12404, Niamey, Niger.

${ }^{3}$ Virologist, IITA, Oyo Road, PMB 5320, Ibadan, Nigeria.

${ }^{4}$ Principal Research Fellow, Plant Environment Laboratory, Department of Agriculture, University of Reading, Cutbush Lane, Shinfield, Reading, RG2 9AF, UK.

${ }^{5}$ Senior Scientific Officer and Principal Scientist respectively, ICRISAT, BP 320, Bamako, Mali.

*Corresponding author: S. N. Nigam (email: s.nigam@cgiar.org)
}

reduce aflatoxin contamination in farmers' fields. It is expected that transgenic resistance against fungal infection and aflatoxin production in combination with conventional breeding efforts may lead to the development of agronomically superior peanuts that are free of aflatoxin contamination.

Key Words: Groundnut, Arachis hypogaea, Aspergillus flavus, preharvest seed infection, in vitro seed colonization, on-farm evaluation.

The problem of aflatoxin (produced by the Aspergillus group of fungi) contamination in peanut was first recognized in 1960 following outbreaks of Turkey-X disease in the United Kingdom. For a long time it was considered a postharvest problem. Rao and Tulpule (1967) were the first to report varietal differences in resistance to aflatoxin production in peanut. In their laboratory study the introduced genotype US 26 (PI 246388) did not support aflatoxin production when colonized by aflatoxin producing strain of $A$. flavus. However, other researchers could not support this finding. Mixon and Rogers (1973) were the first to suggest the use of resistant cultivars to contain the problem of aflatoxin contamination in peanut. They developed a laboratory method to screen peanut genotypes for resistance to seed invasion and colonization by $A$. flavus and $A$. parasiticus using rehydrated mature seeds. They reported two Valencia genotypes, PI 337394 F and PI 337409, as having high levels of resistance to in vitro seed colonization (IVSC) by both pathogens.

The Groundnut Improvement Program was established at the International Crops Research Institute for the Semi-Arid Tropics (ICRISAT) in 1976 and assigned a high priority to contain the aflatoxin problem in peanut. Taking the lead from Mixon and his group's work, PI 337394 F and PI 337409 were obtained from the USA and extensively used in hybridization programs. However, it was realized that significant invasion of apparently undamaged peanut pods by $A$. flavus and $A$. parasiticus and subsequent aflatoxin contamination 
can occur in the field before harvest (Davidson et al., 1983; Mehan et al., 1986). The moisture and heat stress during pod development, damage to the pods by insect pests and nematodes, and other injury during cultural operations facilitate preharvest seed infection (Mehan et al., 1991b). Once infection is established it cannot be undone through postharvest operations or in storage. Following appropriate drying, curing and storage practices, postharvest aflatoxin contamination can be minimized. However, these practices fail if the aflatoxin is already present in the seed before drying and storage. Thus, resistance to preharvest aflatoxin contamination (seed infection and aflatoxin production) remains a key issue in breeding for resistance to aflatoxin contamination. If resistance to preharvest aflatoxin contamination is found, then much of this problem will be solved because it also will confer resistance to postharvest aflatoxin production.

\section{Genetic enhancement for resistance to aflatoxin contamination in peanut}

Resistance barriers. The pathogen has to cross two barriers before it can reach cotyledons to derive its sustenance. The first interaction between the pathogen and the host is at the pod wall which is a physical barrier and resistance is attributed to pod shell structure (Zambettakis, 1975). Even if available at higher levels, pod wall resistance will have little practical value because ease of shelling is an important consideration in the economics of peanut cultivation. Any unusual interference with the pod wall will make a variety economically nonviable. Thus, improvement in pod shell traits was not pursued at ICRISAT.

The second barrier to the pathogen is the seed coat. This resistance is attributed to thickness and density of palisade layers, presence of wax layers, and absence of fissures and cavities (LaPrade, 1973; LaPrade et al., 1973; Zambettakis, 1975; Pettit et al., 1989; Liang et al., 2006). There are conflicting reports regarding the role of fungistatic phenolic compounds in imparting resistance at the seed coat level. Moisture and heat stress during pod development can cause microscopic fissures in seed coat (Dickens, 1977; Glueck et al., 1977). Similarly, insect and nematode damage to the developing pods in the soil can provide entry points to the fungal pathogen through the pod wall and seed coat. Seed coatrelated resistance will have little value in the case of decorticated seed or when the testa is damaged.

The ultimate feeding site for fungi is the cotyledons in the seed and this is where aflatoxins are produced. If cotyledons do not provide sustenance to the pathogen, there would be no or little production of aflatoxin.
The relationships between laboratory and field infection. The relationships between in vitro seed colonization (IVSC) and natural seed infection and aflatoxin production in the field and their contribution in reducing aflatoxin contamination are not understood. A majority of the IVSC resistant lines tested by Mehan et al. (1987, 1988) did not show resistance to preharvest seed infection. IVSC and seed infection in the field are reported to be two independent genetic events (Utomo et al., 1990; Upadhyaya et al., 1997). Similarly, no correlations are reported between aflatoxin content, colonization of seed or shells and population densities of $A$. flavus in the soil (Will et al., 1994). There are highly significant $G \times E$ interactions for preharvest seed infection and aflatoxin production (Nigam, 2002). Xue et al. (2004a) also did not find a strong relationship among the three types of resistance. She also reported significant interactions between peanut genotypes and pathogen strains. Knowledge of these relationships and their contributions to the solution of the problems is essential to devise appropriate strategies for breeding for resistance to aflatoxin contamination.

Inheritance of aflatoxin resistance. Very little is known about the inheritance of resistance to preharvest seed infection, IVSC, or aflatoxin production. A few published reports give information on broad sense heritability (low to moderate) and combining ability of resistance sources (Rao et al., 1989; Utomo et al., 1990; Upadhyaya et al., 1997; Xue, 2004). Utomo et al. (1990) reported a lack of significant relationships among the three resistance mechanisms and concluded that different genes governed them. Upadhyaya et al. (2002) also indicated that the three components of resistance are inherited independently. Xue (2004) reported predominantly nonadditive genetic variance for aflatoxin production, suggesting that selection for this trait in early generations will be ineffective. The genetics of resistance mechanisms is not clearly established. Further, the allelic relationship among various sources for each resistance trait needs to be elucidated for defining better strategies for breeding for resistance to aflatoxin contamination.

Status of aflatoxin resistance breeding at ICRISAT

Resistant sources of germplasm. Sources of all the three types of resistance (preharvest seed infection, IVSC, and aflatoxin production by $A$. flavus) have been reported in cultivated peanut.

In earlier screenings of germplasm accessions for their reaction to IVSC at ICRISAT, Patancheru, India, resistance $(15 \%$ or fewer seeds colonized) of three genotypes, PI 337394 F, PI 337409 and UF 71513 was confirmed and six new sources of resistance (Ah 78223, J 11, U 4-47-7, Var. 27, 
Faizpur, and Monir 240-30) were identified (Mehan, 1989). Resistance of PI 337394 F, PI 337409 and $\mathbf{J} 11$ was also confirmed by other researchers in Senegal (Zambettakis et al., 1981) and USA (Kisyombe et al., 1985).

Over the years, about 2000 peanut accessions have been screened for their resistance to A. flavus seed infection in a sick plot under imposed drought conditions at ICRISAT Center, India. The 21 genotypes identified as resistant $(\leq 2 \%$ seed infection) were as follows: ICG 1122 (alternate identity: Lin Yuch Tsao; origin: China), ICG 1173 (alternate identity: AH 61; origin: India), ICG 1323 (alternate identity: HG 1; origin: India), ICG 1326 (alternate identity: J 11; origin: India), ICG 1859 (alternate identity: EC 6902; origin: unknown), ICG 1994 (alternate identity: TG 6; origin: India), ICG 3263 (alternate identity: U 4-47-7; origin: Uganda), ICG 3267 (alternate identity: U 4-47-14; origin: USA), ICG 3336 (alternate identity: Exotic 6; origin: unknown), ICG 3700 (alternate identity: AH 7223; origin: Nigeria), ICG 4589 (alternate identity: Exotic 2; origin: unknown), ICG 4749 (alternate identity: PI 337394 F; origin: Argentina), ICG 4888 (alternate identity: AH 7827; origin: China), ICG 7412 (alternate identity: 277/71; origin: Zimbabwe), ICG 7633 (alternate identity: UF 71513; origin: USA), ICG 8666 (alternate identity: Schwarz 21; origin: Indonesia), ICG 9407 (alternate identity: 61-40; origin: Senegal), ICG 9610 (alternate identity: VRR 538; origin: India), ICG 10020 (alternate identity: PI 476149; origin: Peru), ICG 10094 (alternate identity: S 4; origin: Zimbabwe) and ICG 10933 (alternate identity: PI 476166; origin: Peru) (Singh et al., 1997).

In spite of significant $G \times E$ interaction reported for resistance to seed infection, some accessions such as ICG 1326, ICG 3263, ICG 3336, ICG 3700, ICG 4749 and ICG 7633 showed consistent resistance to seed infection in India and Senegal (Mehan et al., 1991a). Most of these accessions were also screened for resistance to IVSC. Accessions ICG 1326, ICG 3263, ICG 3700, ICG 4749, ICG 4888, ICG 7633 and ICG 9407 also showed resistance to IVSC and are of special interest in aflatoxin resistance breeding program.

In a recent evaluation of $49 \mathrm{~A}$. hypogaea genotypes over $3 \mathrm{yr}$ (1999-2001, Waliyar et al., unpublished) at the ICRISAT Sahelian Center in Sadore, Niger, 29 accessions were resistant $(\leq 10 \%$ seed infection compared to $70 \%$ for susceptible control JL 24). These included J 11 (resistant control), ICG 9610, ICG 1323, ICG 10094, ICG 9407, ICG 3263, ICG 4749, ICG 1859, ICG 4589, and ICG 7633, which were also reported as resistant from screenings done at the ICRISAT Center, India. Other genotypes which fell into the resistant group included ICG 10609, ICG 11682, ICG 10615, ICG 6760, ICG 23, ICG 7, ICG 51, ICG 45, ICG 27, ICG 2051, ICG 11480, ICG 6101, ICG 6754, ICG 2925, ICG 6291, ICG 10220, ICG 74175, and ICG 4437. ICG 10609 and ICG 11686 (each with 4\% seed infection) had the same level of seed infection as the two resistant controls 55-437 (3\% seed infection) and $\mathrm{J} 11$ (4\% seed infection). Aflatoxin levels in 29 resistant genotypes ranged from 0.4 to $3.5 \mu \mathrm{g} \mathrm{kg}^{-1}$ versus $86.6 \mu \mathrm{g} \mathrm{kg}^{-1}$ for the susceptible control JL 24. ICG 10609 and ICG 11682 (each with $0.4 \mu \mathrm{g} \mathrm{kg}^{-1}$ aflatoxin content) were similar to the resistant control 55-437 $\left(0.5 \mu \mathrm{g} \mathrm{kg}^{-1}\right)$ in aflatoxin content. Similarly, ICG $10615\left(0.6 \mu \mathrm{g} \mathrm{kg}^{-1}\right)$, ICG $6760\left(0.6 \mu \mathrm{g} \mathrm{kg}^{-1}\right)$, ICG $23\left(0.7 \mu \mathrm{g} \mathrm{kg}^{-1}\right)$ and, ICG $9610\left(0.7 \mu \mathrm{g} \mathrm{kg}^{-1}\right)$ were not significantly different from the second resistant control J $11\left(0.8 \mu \mathrm{g} \mathrm{kg}^{-1}\right)$.

During the 2005 rainy season, 24 aflatoxin resistant germplasm lines were reevaluated in the field and under in vitro conditions at the ICRISAT Center, India. Ten germplasm lines (ICG 1859, ICG 1994, ICG 1326, ICG 3267, ICG 10094, ICG 3241, ICG 1422, ICG 3251, ICG 9820, and ICG 4160) showed no preharvest seed infection or aflatoxin production.

Thakur et al. (2000) observed wide variation both for IVSC and aflatoxin production among the 35 accessions belonging to 24 species in six different sections of the genus Arachis. Four accessions $A$. pusilla [ICG 13212 (PI 497572, VSW 6773)], $A$. chiquitana Krapov., W.C. Gregory and C.E. Simpson [ICG 11560 (PI 476004, KSSC 36025)], A. triseminata. Krapov. and W.C Gregory [ICG 8131 (PI 338449, GK 12922) and ICG 14875 (VfaPzSv 130800)] recorded low IVSC and produced low levels of aflatoxin compared with control J 11. Xue et al. (2004b) recorded very low levels of aflatoxin in A. duranensis Krapov. and W.C. Gregory accessions PI 468319, PI 468200, and PI 262133 and PI 262141 and PI $475997 A$. cardenasii Krapov. and W. C. Gregory accessions and recommended them as valuable sources of resistance to aflatoxin contamination.

The value of resistance sources depends upon levels and stability of their resistances. Many genotypes have shown high levels of resistance against preharvest seed infection, IVSC, and aflatoxin production, significant $\mathrm{G} \times \mathrm{E}$ interaction remains a major issue in screening for aflatoxin resistance. Nonetheless, there are several genotypes including ICG 7633, ICG 4749, ICG 1326, ICG 3263, ICG 9407, ICG 10094, ICG 1859, and ICG 9610 which have shown consistently high levels of 
resistance across tests and locations, which make them good candidates for use in a resistance breeding program. It would be worthwhile to make an international screening nursery of such genotypes for extensive evaluation across diverse growing environments to identify stable sources with high levels of combined resistance to seed infection, IVSC, and aflatoxin production.

Progress in resistance breeding. In the past, resistance to IVSC received major attention because of ease of screening and also because aflatoxin contamination was considered a postharvest problem. The available genetic resistance was transferred to superior agronomic backgrounds and several advanced breeding lines were released in the USA and India. However, none showed marked superiority in resistance over the resistant parent. When it was realized that $A$. flavus infection can also occur before harvest, preharvest infection and aflatoxin production in the field became the traits of major interest in resistance breeding. Using 55-437, Tamnut 74, and PI 365553 (for resistance to preharvest seed infection), PI 337394 F, PI 337409, UF 71513, UF 71513-1, Ah 7223, J 11, U 4-47-7, Var 27, Faizpur, and Monir 240-30 (for resistance to IVSC) and U 4-7-5 and VRR 245 (for resistance to aflatoxin production) elite breeding lines such as ICGV 88145, ICGV 89104, ICGV 91278, ICGV 91283, and ICGV 91284 were developed and released as improved germplasm (Rao et al., 1995; Upadhyaya et al., 2001). Three other breeding lines, ICGV 87084, ICGV 87094, and ICGV 87110 were found resistant to preharvest seed infection when tested in Niger, Senegal and Burkina Faso in West Africa (Waliyar et al., 1994).

In a recent 2-year evaluation of introduced genotypes at the Crops Research Institute, Guangzhou, China, ICGV 95440, ICGV 95422, ICGV 94435, ICGV 94434, ICGV 94433, ICGV 95435, and UF 71315 showed high levels of resistance to seed invasion by $A$. flavus (Zhou et al., 2002). Of these, ICGV 95440, ICGV 95422, ICGV 94435, ICGV 95435, and UF 71315 also had much lower $\left(<10 \mu \mathrm{g} \mathrm{g}^{-1}\right)$ aflatoxin production. Except for UF 71315, all genotypes were developed at the ICRISAT Center, India in an aflatoxin resistance breeding program.

Performance of some of the recently developed breeding lines is given in Tables 1 and 2. In spite of high standard errors and coefficients of variation and $\mathrm{G} \times \mathrm{E}$ interactions, these lines have consistently had low preharvest seed infection and aflatoxin production over years and locations. It is interesting to note that some of the lines with zero detectable preharvest seed infection also had some aflatoxin production. This clearly illustrates the need for an effective sampling procedure for estimation of preharvest seed infection and subsequent aflatoxin production. Despite considerable efforts for genetic enhancement, stable resistance to A. flavus infection/aflatoxin contamination has been limited due to the high $\mathrm{G} \times \mathrm{E}$ interactions (Nigam, 2002).

\section{On-farm performance of aflatoxin resistant ad- vanced breeding lines}

Cultivation of resistant varieties would be a simple and effective option for farmers, but cultivars with high levels of resistance to aflatoxin contamination and good agronomic characteristics are not available. Fourteen advanced breeding lines with resistance to IVSC including, ICGV 91278, ICGV 91279, ICGV 91283, ICGV 91284, ICGV 91315, ICGV 91317, ICGV 91324, ICGV 91328, ICGV 91341, ICGV 92302, ICGV 93305, ICGV 93328, ICGV 93379, and ICGV 94434, were evaluated from 2003 to 2006 period for seed infection and aflatoxin contamination as well as agronomic performance in farmer participatory, multi-locational on-farm trials in Anantapur and Chittoor districts in Andhra Pradesh, India.

2003 and 2004 rainy seasons. All 14 advanced breeding lines along with local variety, TMV 2, were evaluated in nine farmers' fields in three villages in each district following farmers' practices of cultivation. All the test genotypes produced 12 $45 \%$ higher pod and haulm yields than TMV 2. Aflatoxin contamination ranged between 0 $7 \mu \mathrm{g} \mathrm{kg}^{-1}$ in all the test lines at all locations compared with 0 to $>150 \mu \mathrm{g} \mathrm{kg}^{-1}$ in TMV 2 . Based on their performance, farmers in Chittoor selected ICGV 91341, ICGV 93305, ICGV 94379, and ICGV 94434, and farmers in Anantapur chose ICGV 91278, ICGV 91328, ICGV 94379, and ICGV 94434 for further evaluation and adoption. These materials have good tolerance to drought, high pod and haulm yields, good fodder quality, good shelling outturn, and low aflatoxin risk.

2005 rainy season. All the selected breeding lines (four each in both districts) produced 16-61\% higher pod and haulm yields and had 36-73\% reduction in aflatoxin contamination over TMV 2.

2006 rainy season. Due to severe drought conditions during the 2006 rainy season in Andhra Pradesh, a trial was conducted with only the two breeding lines where enough seed was available (ICGV 94379 and ICGV 94434) and restricted to six farmers' fields in two villages in Anantapur. Overall, both lines produced about $11 \%$ higher mean pod yield at both locations against the control yield $1010 \mathrm{~kg} \mathrm{ha}^{-1}$. Both lines also showed $57-71 \%$ reduction in aflatoxin contamination as compared to $177 \mu \mathrm{g} \mathrm{kg}^{-1}$ in control TMV 2. 


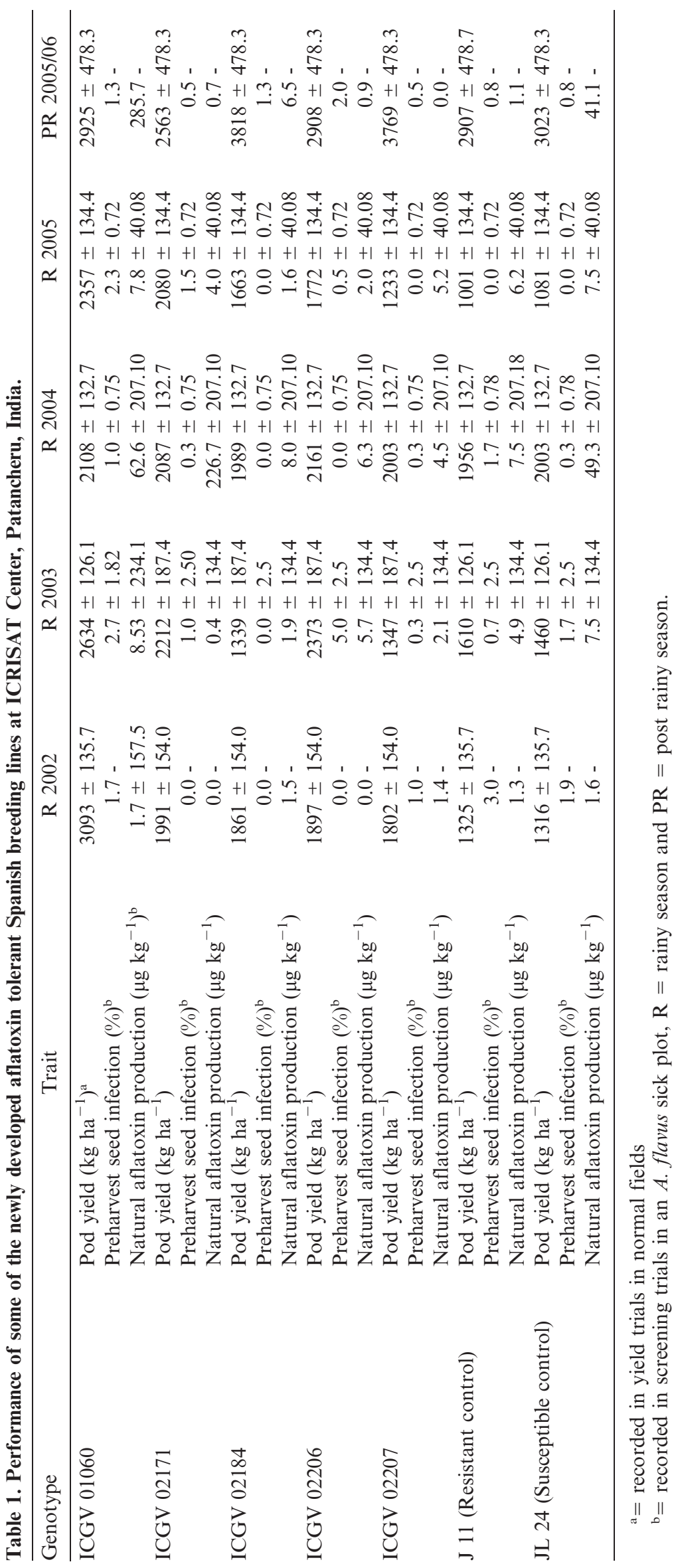


Table 2. Performance of some of the newly developed aflatoxin tolerant Spanish breeding lines at ICRISAT Center, Patancheru, India.

\begin{tabular}{|c|c|c|c|c|c|c|}
\hline \multirow[b]{2}{*}{ Genotype } & \multicolumn{2}{|c|}{ Pod yield $\left(\mathrm{kg} \mathrm{ha}^{-1}\right)^{\mathrm{a}}$} & \multicolumn{2}{|c|}{$\operatorname{IVSC}(\%)^{\mathrm{b}}$} & \multicolumn{2}{|c|}{ Natural aflatoxin production $\left(\mu \mathrm{g} \mathrm{kg}^{-1}\right)^{\mathrm{b}}$} \\
\hline & R 2005 & PR 2005/06 & R 2005 & PR 2005/06 & R 2005 & PR 2005/06 \\
\hline ICGV 03328 & 2095 & 2790 & 0.0 & 1.8 & 1.9 & 0.5 \\
\hline ICGV 03331 & 2136 & 3532 & 0.0 & 1.3 & 2.8 & 1.5 \\
\hline ICGV 03332 & 1808 & 3042 & 0.0 & 2.3 & 4.8 & 0.7 \\
\hline ICGV 03346 & 1786 & 3485 & 0.0 & 2.0 & 4.9 & 1.1 \\
\hline J 11 (Resistant control ) & 1435 & 2424 & 0.0 & 8.9 & 18.9 & 9.8 \\
\hline JL 24 (Susceptible control ) & 1603 & 3137 & 0.0 & 9.6 & 25.6 & 222.0 \\
\hline $\mathrm{SE}( \pm)$ & 113.1 & 292.2 & 0.65 & 1.48 & 1.69 & 215.7 \\
\hline $\mathrm{CV}(\%)$ & 8.1 & 13.1 & 343.7 & 113.0 & 101.2 & 515.6 \\
\hline
\end{tabular}

${ }^{\mathrm{a}}=$ recorded in yield trials in normal fields,

$\mathrm{b}=$ recorded in screening trials in an $A$. flavus sick plot, $\mathrm{R}=$ rainy season and $\mathrm{PR}=$ postrainy season.

2007 rainy season. ICGV 91278, ICGV 94379, and ICGV 94434 are being tested in 42 farmers' fields in six villages in Anantapur, and ICGV 91341, ICGV 93305, ICGV 94379, and ICGV 94434 were evaluated in 15 farmers' fields in three villages in Chittoor. The results from these evaluations are currently being analyzed. Simultaneously, farmers were trained in postharvest aflatoxin management methods and utilization of mechanical threshers for rapid separation of pods from plants instead of beating them against hard objects.

Summary. This study has clearly demonstrated that available genetic resistance combined with simple postharvest management practices can be an effective option for mitigating $A$. flavus seed infection and aflatoxin contamination at the farm level in peanut. Attempts are being made to outscale these varieties to diverse regions in India.

\section{Limitations of conventional breeding}

A resistance breeding program requires that gene(s) for resistance and a reliable, efficient and simple screening technique (including sampling procedures) are available. The presence of the latter is over riding as it helps to detect the presence of resistance genes, their level of resistance and nature of inheritance, prevents escapes in a largescale breeding program, and gives results that are repeatable across locations and years.

Conventional breeding can reshuffle genes and bring out desirable combinations among and between the available genes to harness their cumulative or complementary benefits, but it cannot create new genes. The level(s) of resistance with available gene(s) in the germplasm pool places a ceiling on the progress that can be made by conventional breeding. Lack of high levels of resistance to preharvest seed infection and aflatoxin production in the field and IVSC and aflatoxin production (although some genotypes have stable resistance), high $\mathrm{G} \times \mathrm{E}$ interaction for these traits, and limitations of screening techniques in giving reliable and repeatable results place severe limitations on the progress in resistance breeding to eliminate aflatoxin. Even if highly resistant gene(s) are utilized from other sources through nonconventional means, the need for an efficient and reliable screening technique still remains for field verification of the resistant products.

Under the present circumstances, genetic resistance alone cannot eliminate the problem of aflatoxin contamination in peanut unless it is accompanied with other cultural management practices such as soil amendments, bio-control, soil water management, soil pest control, and proper drying and curing and storage. Other plant traits such as short-duration (with high partitioning to reproductive tissues) to match the period of soil moisture availability to avert terminal moisture stress, uniform pod maturity, and longer root systems to extract moisture from the deeper soil layers to maintain plant-water status may also help to some extent to mitigate the problem of aflatoxin contamination. Holbrook et al. (2000a) suggested use of leaf temperature and visual drought stress ratings for indirectly selecting for low preharvest aflatoxin contamination. However, at ICRISAT, drought tolerant advanced breeding lines, when evaluated for preharvest aflatoxin contamination, were found susceptible (Nigam et al., unpublished). Steps needed to improve the efficiency of conventional breeding approach

Aflatoxin contamination in the field is the result of host plant $\times$ pathogen $\times$ environment interactions. Because peanut being a subterranean crop and the pathogen also inhabits the soil, the plantpathogen interaction is very complex. Aflatoxin contamination is a rare event and occurs only when all the conditions in and around a geocarposphere are favorable. Not all seeds in a plant are infected. Intra- and inter-plant variation in aflatoxin contamination of the seeds can be many fold. Unless 
screening techniques are able to minimize these variations under field conditions, the success in aflatoxin resistance breeding will remain a chance event. Therefore, the first priority should be on development of reliable screening techniques to make them more reproducible under field conditions. Once a screening technique is perfected, the search for resistance gene(s) can be vigorously pursued. Stability of resistance gene(s) in multiple environments can be evaluated against variable Aspergillus species and strains and their pathogenicity tested. Alternately, a mixture of several aflatoxigenic strains of $A$. flavus and $A$. parasiticus can be used in screening genotypes for stable low aflatoxin production (Xue, 2004). Allelic relationships between resistant parents can be studied to devise better breeding strategies to accumulate diverse genes in a common genetic background and to improve the level of resistance to aflatoxin contamination. The priority in aflatoxin resistance breeding should be on resistance to aflatoxin production and preharvest seed infection. For gene pyramiding, genes responsible for IVSC could also be harnessed to reinforce the defense against the pathogen both in the field and during seed storage.

Wild Arachis species are reported to have genetic variation for IVSC and aflatoxin production (Thakur et al., 2000; Xue et al., 2004b). Wild Arachis, particularly those cross-compatible with the cultivated peanut, need to be studied more thoroughly for resistance to aflatoxin production, preharvest infection and IVSC as they may have unique gene(s) for these traits which could help to improve the level of resistance in cultivated types. Xue et al. (2004b) suggested to identify polymorphic markers in GP-NC WS 2, an interspecific derivative between A. hypogaea PI 261942 and $A$. cardenasii 10017, and develop populations for marker-assisted selection. They stated that use of molecular markers tightly linked to aflatoxin resistance gene(s) will improve selection efficiency.

Although fatty acid concentrations accounted for significant portions of genetic variation in their laboratory screening for postharvest contamination, Xue et al. (2005) did not recommend them for use as predictors for susceptibility to aflatoxin contamination especially for lines in the normal range for oleate and linoleate. Holbrook et al. (2000b) did not find any measurable effect of lines with low linoleic acid on preharvest aflatoxin contamination. The underlying mechanism(s) associated with resistance to preharvest infection, IVSC and aflatoxin production and their relationships are not fully known. Once we understand these factors contributing significantly to the resistance, we can bring them together in a selection index. The selection index should not only include factors imparting resistance to preharvest seed infection but also those factors which give resistance to aflatoxin production and IVSC.

\section{Conclusions}

The lack of high levels of resistance to aflatoxin contamination in the cultivated peanut germplasm places a ceiling on the progress that can be made following conventional approach in resistance breeding. The search for better sources of resistance in the cultivated and wild Arachis germplasm needs to be pursued more vigorously. Simultaneously, screening techniques and sampling procedures should be further refined to produce reproducible results. Technological advances in genetic engineering may provide an alterative way to overcome the problem of aflatoxin contamination in peanut. Recent advances in this area through modification of aflatoxin biosynthesis pathway or use of genes with antifungal properties may lead to the development of transgenic peanut events with high and stable levels of resistance to fungal infection and aflatoxin production (Sharma et al., 2006). Such events can be used in conventional breeding to develop agronomically superior peanut varieties that are highly resistant to aflatoxin contamination.

\section{Literature Cited}

Davidson, J.I., R.I. Hill, Jr., R.J. Cole, A.C. Mixon, and R.J. Henning. 1983. Field performance of two peanut cultivars relative to aflatoxin contamination. Peanut Sci. 10:43-47.

Dickens, J.W. 1977. Aflatoxin, occurrence and control during growth, harvest and storage of peanuts, pp. 99-105. In J.V. Rodricks, C.W. Hesseltine, and M.A. Mehlman (eds.). Mycotoxins in Human and Animal Health. Park Forest South, IL: Pathotox Publishers.

Glueck, J.A., L.E. Clark, and O.D. Smith. 1977. Testa comparisons of four peanut cultivars. Crop Sci. 17:777-782.

Holbrook, C.C., C.K. Kvien, K.S. Ruker, D.M. Wilson, J.E. Hook, and M.E. Matheron. 2000a. Preharvest aflatoxin contamination in drought-tolerant and drought-intolerant peanut genotypes. Peanut Sci. 27:45-48.

Holbrook, C.C., D.M. Wilson, M.E. Matheron, J.E. Hunter, D.A. Knauft, and D.W. Gorbet. 2000b. Aspergillus colonization and aflatoxin contamination in peanut genotypes with reduced linoleic acid composition. Plant Dis. 84:148-150.

Kisyombe, C.T., M.K. Beute, and G.A. Payne. 1985. Field evaluation of peanut genotypes for resistance to infection by Aspergillus parasiticus. Peanut Sci. 12:12-17.

LaPrade, J.C. 1973. Physical and chemical properties of resistance exhibited by certain genotypes of Arachis hypogaea to invasion by aflatoxin producing Aspergillus spp. Ph.D. Thesis. University of Florida, USA. 76 pp.

LaPrade, J.C., J.A. Bartz, A.J. Norden, and T.J. DeMuynk. 1973. Correlation of peanut seed-coat surface wax accumulations with tolerance to colonization by Aspergillus flavus. Proc. Amer. Peanut Res. and Educ. Assoc. 5:89-94.

Liang, X.Q., M. Luo, and B.Z. Guo. 2006. Resistance mechanisms to Aspergillus flavus infection and aflatoxin contamination in peanut (Arachis hypogaea). Plant Pathology J. 5:115-124. 
Mehan, V.K. 1989. Screening groundnuts for resistance to seed invasion by Aspergillus flavus and to aflatoxin production, pp. 323-334. In D. McDonald and V.K. Mehan (eds.), Aflatoxin Contamination of Groundnut. Proc. Int. Workshop, 6-9 Oct. 1987, ICRISAT Center, India. Patancheru, A.P. 502 324, India. International Crops Research Institute for the Semi-Arid Tropics.

Mehan, V.K., A. Ba, D. McDonald, J.L. Renard, R.C.N. Rao, and S. Jayanthi. 1991a. Field screening of groundnuts for resistance to seed infection by Aspergillus flavus. Oléagineux 46:109-118.

Mehan, V.K., D. McDonald, L.J. Haravu, and S. Jayanthi. 1991b. The Groundnut Aflatoxin Problem: Review and Literature Database. Patancheru, A.P. 502 324, India. International Crops Research Institute for the Semi-Arid Tropics.

Mehan, V.K., D. McDonald, and N. Ramakrishna. 1987. Resistance of peanut genotypes to seed infection by Aspergillus flavus in field in India. Peanut Sci. 14:17-21.

Mehan, V.K., D. McDonald, and N. Ramakrishna. 1988. Effects of adding inoculum of Aspergillus flavus to pod-zone soil on seed infection and aflatoxin contamination of peanut genotypes. Oléagineux 43:21-28.

Mehan, V.K., D. McDonald, N. Ramakrishna, and J.H. Williams. 1986. Effects of genotype and date of harvest on infection of peanut seed by Aspergillus flavus and subsequent contamination with aflatoxin. Peanut Sci. 13:46-50.

Mixon, A.C. and K.M. Rogers. 1973. Peanut accessions resistant to seed infection by Aspergillus flavus. Agron. J. 65:560-562.

Nigam, S.N. 2002. Aflatoxin management: Host-plant resistance, 16 pp. In Aflatoxin Detection, Quantitative Estimation and Management. Proc. of a Consultative Meeting, 8-9 Jan. 2001, ICRISAT Patancheru. Scottish Crop Research Institute, Invergowrie, Dundee, DD2 5DA, UK.

Pettit, R.E., H.A. Azaizeh, R.A. Taber, J.B. Szerszen, and O.D. Smith. 1989. Screening groundnut cultivars for resistance to Aspergillus flavus, Aspergillus parasiticus, and aflatoxin contamination, pp. 291-303. In D. McDonald and V.K. Mehan (eds.), Aflatoxin Contamination of Groundnut. Proc. Int. Workshop, 6-9 Oct. 1987, ICRISAT Center, India. Patancheru, A.P. 502 324, India. International Crops Research Institute for the Semi-Arid Tropics.

Rao, K.S. and P.G. Tulpule. 1967. Varietal differences of groundnut in the production of aflatoxin. Nature (London) 214:738-739.

Rao, M.J.V., S.N. Nigam, V.K. Mehan, and D. McDonald. 1989. Aspergillus flavus resistance breeding in groundnut: Progress made at ICRISAT Center, pp. 345-355. In D. McDonald and V.K. Mehan (eds.), Aflatoxin Contamination of Groundnut. Proc. Int. Workshop, 6-9 Oct. 1987, ICRISAT Center, Patancheru, A.P. 502 324, India. International Crops Research Institute for the SemiArid Tropics.

Rao, M.J.V., H.D. Upadhyaya, V.K. Mehan, S.N. Nigam, D. McDonald, and N.S. Reddy. 1995. Registration of peanut germplasm ICGV 88145 and ICGV 89104 resistant to seed infection by Aspergillus flavus. Crop Sci. 35:1717.

Sharma, K.K., P. Bhatnagar-Mathur, K. Sai-Vishnu-Priya, V. Anjaiah, V. Vadez, F. Waliyar, P. Lava Kumar, S.N. Nigam, and D.H. Hoisington. 2006. Genetic engineering of groundnut for crop improvement, $44 \mathrm{pp}$. In Groundnut Aflatoxin Management and Genomics. Program and Book of Abstract. International Conf., 5-9 Nov. 2006, Guangzhou, Gungdong, China. Crops Research Institute, Guangdong Academy of Agricultural Sciences.

Singh, A.K., V.K. Mehan, and S.N. Nigam. 1997. Sources of resistance to groundnut fungal and bacterial diseases: an update and appraisal. (In En. Summaries in En., Fr.) Information Bulletin no. 50. Patancheru 502 234, Andhra Pradesh, India: International Crops Research Institute for the Semi-Arid Tropics. 48 pp.
Thakur, R.P., V.P. Rao, S.V. Reddy, and M. Ferguson. 2000. Evaluation of wild Arachis germplasm accessions for in vitro seed colonization and aflatoxin production by Aspergillus flavus. International Arachis Newsletter 20:44-46.

Upadhyaya, H.D., S.N. Nigam, and R.P. Thakur. 2002. Genetic enhancement for resistance to aflatoxin contamination in groundnut, pp. 29-36. In Summary Proceedings of the Seventh ICRISAT Regional Groundnut Meeting for Western and Central Africa, 6-8 Dec. 2000, Cotonou, Benin. Patancheru 502 324, Andhra Pradesh, India: International Crops Research Institute for the Semi-Arid Tropics.

Upadhyaya, H.D., S.N. Nigam, V.K. Mehan, and J.M. Lenne. 1997. Aflatoxin contamination of groundnut - prospects of a genetic solution through conventional breeding, pp. 81-85. In Aflatoxin Contamination Problems in Groundnut in Asia: Proceedings of the First Working Group Meeting, 27-29 May 1996, Ministry of Agriculture and Rural Development, Hanoi, Vietnam (V.K. Mehan and C.LL. Gowda eds.). Patancheru 502 324, Andhra Pradesh, India: International Crops Research Institute for the Semi-Arid Tropics.

Upadhyaya, H.D., S.N. Nigam, V.K. Mehan, A.G.S. Reddy, and N. Yellaiah. 2001. Registration of Aspergillus flavus seed infection resistant peanut germplasm ICGV 91278, ICGV 91283, and ICGV 91284. Crop Sci. 41:599-600.

Utomo, S.D., W.F. Anderson, J.C. Wynne, M.K. Beute, W.M. Hagler, Jr., and G.A. Payne. 1990. Estimates of heritability and correlation among three mechanisms of resistance to Aspergillus parasiticus in peanut. Proc. Amer. Peanut Res. and Educ. Soc. 22:26. (abstr.).

Waliyar, F., H. Hassan, S. Bonkoungou, and J.P. Bosc. 1994. Sources of resistance to Aspergillus flavus and aflatoxin contamination in groundnut genotypes in West Africa. Plant Dis. 78:704-708.

Will, M.E., C.C. Holbrook, and D.M. Wilson. 1994. Evaluation of field inoculation techniques for screening peanut genotypes for reaction to preharvest $A$. flavus group infection and aflatoxin contamination. Peanut Sci. 21:122-125.

Xue, H. 2004. Evaluation of peanut (Arachis hypogaea L.) germplasm for resistance to aflatoxin production by Aspergillus flavus Link ex Fries. Ph.D. Thesis. North Carolina State University, Raleigh, NC.

Xue, H.Q., T.G. Isleib, G.A. Payne, W.F. Novitzky, and G. OBrian. 2005. Aflatoxin production in peanut lines selected to represent a range of linoleic acid concentrations. J. Food Protection 68:126-132.

Xue, H.Q., T.G. Isleib, G.A. Payne, and G. OBrian. 2004a. Evaluation of postharvest aflatoxin production in peanut germplasm with resistance to seed colonization and preharvest aflatoxin contamination. Peanut Sci. 31:124-134.

Xue, H.Q., T.G. Isleib, H.T. Stalker, G.A. Payne, and G. OBrian. 2004b. Evaluation of Arachis species and interspecific tetraploid lines for resistance to aflatoxin production by Aspergillus flavus. Peanut Sci. 31:134-141.

Zambettakis, C. 1975. [Study of the contamination of several varieties of groundnut by Aspergillus flavus.]. Etude de la contamination de quelques variétés d'arachide par Aspergillus flavus. Oléagineux 30:161-167.

Zambettakis, C., F. Waliyar, Bockelee-Morvan, and O. de Pins. 1981. Results of four years of research on resistance of groundnut varieties to Aspergillus flavus. Oléagineux 36:377-385.

Zhou Gui-yuan, Xuan-qiang Liang, Yi-cong Li, Shao-xiong Li, and Sui-lin Li. 2002. Evaluation and application of introduced peanut cultivars for resistance to Aspergillus flavus invasion. Jour. Peanut Sci. 31:14-17. (In Chin, Abstr in En) 